BENSAÏD, Daniel. Marx, manual de instruções. São Paulo: Boitempo Editorial, 2013.

\section{O “OUTRO” MARX OU A HERESIA MARXISTA DE DANIEL BENSAÏD}

Fabio Mascaro Querido

Filósofo e militante francês, falecido em janeiro de 2010, Daniel Bensaïd (1946) notabilizouse por uma das mais ambiciosas tentativas contemporâneas de reinterpretar o pensamento de Karl Marx à luz das condições de possibilidade do presente. Sob os escombros dos diversos marxismos do século XX, o filósofo francês retorna a Marx não para resgatá-lo da incompreensão geral, recuperando os "verdadeiros" fundamentos do seu pensamento, e sim para oxigená-lo a partir da sua confrontação crítica com os desafios do presentedaí a tentativa de buscar novas pistas e novos caminhos, comumente pouco frequentados. Mais do que responder, mais uma vez, às mesmas questões, tratava-se, para ele, da necessidade de reformulá-las, em um contexto marcado por uma verdadeira "crise civilizatória" (da qual a "crise ecológica” é apenas a expressão mais visível).

Em Marx, manual de instruções, livro ora lançado no Brasil pela Boitempo Editorial (na coleção "Marxismo e literatura", coordenada por Leandro Konder e Michael Löwy), Bensaïd apresenta, em uma forma sintética bastante singular-comprovada pela linguagem carregada de humor e pelos desenhos do cartunista francês Stéphane "Charb”, que ilustram, em outra chave, o conteúdo do texto-, os principais aspectos dessa leitura atualizadora de Marx e da tradição marxista, leitura por ele inaugurada no magistral Marx, $o$ Intempestivo, e em A discordância dos tempos, ambos publicados em 1995, na França.
Para Bensaïd, sobretudo no caso de um autor como Marx, cuja obra se encontra direta ou indiretamente vinculada à prática política de sua época, a herança - sem dono nem fiadores - não é uma coisa inerte: ela é sempre irredutível à sua letra, porquanto envolve também a história de suas interpretações, recepções, assim como das lutas das quais tomou parte. Pelas mutações que sofre ao longo do tempo, e pela vigilância constante das ortodoxias instituídas, a "infidelidade” à letra da obra pode ser, muitas vezes, a melhor demonstração de fidelidade. Pois a herança, no limite, é sempre aquilo que dela fazem os herdeiros, em meio às possibilidades de um presente determinado.

No marxismo "herético" e "infiel" de Walter Benjamin, em especial nas "teses sobre o conceito de história” (1940), Bensaïd encontrou um grande aliado para este trabalho de desconstrução e reconstrução de Marx, visando a acordá-lo de um longo pesadelo dogmático. Em permanente diálogo com Benjamin, cuja obra ocasionou forte impacto em sua trajetória intelectual, Bensaïd visualiza a necessidade, após o dramático desencantamento que se abateu sobre a esquerda política e intelectual, no auge da euforia neoliberal - com direito à proclamação do "fim da história" e da "morte" do marxismo -, de um novo "despertar", um "despertar proustiano", como ele diz em outro texto, no qual o espectro de Marx ressurge na sua função salutar: ser a constante "má-consciência do capitalismo", o agente do negativo que desvenda os seus crimes quase perfeitos.

Em Marx, manual de instruções, o filósofo francês analisa, sob um prisma original e inovador, algumas das principais questões envolvidas na reflexão de Marx: da crítica (de matriz feuerbachiana) do fetichismo religioso e terrestre da juventude à teoria do valor desenvolvida n'O Capital, passando pelo comunismo, a revolução, as crises, a ciência e mesmo a ecologia, dentre outras. Em sua ótica, desde pelo menos 1845, com a "descoberta" do caráter ativo do nascente movimento operário europeu, e com a subsequente superação do "comunismo filosófico" (especulativo), Marx entrevê, na luta de classes, um aspecto cen- 
tral da estruturação social no capitalismo, e o eixo sob o qual gravitam tanto a reprodução da ordem (capitalista) vigente quanto a possibilidade de sua transformação radical. Quando jovem, portanto, a constatação da existência das classes foi, para Marx, inseparável da constatação da centralidade do conflito de classes na sociedade capitalista, conflito sintetizado (mas não esgotado) no antagonismo dinâmico entre burguesia e proletariado.

Isso explica, como revela Bensaïd no terceiro capítulo, porque, mesmo nas grandes construções categoriais de $O$ Capital, qualquer tentativa de se buscar em Marx uma definição simples das classes sociais está fadada ao fracasso (ou ao "sucesso" dos simplificadores). Se não há "amor sem amantes”, conforme disse certa vez o historiador britânico E. P. Thompson, não há, para Marx - na visão de Bensaïd -, classes sem luta e antagonismo de classes. Com efeito, à diferença das sociologias classificatórias, a "antisssociologia" ou "sociologia crítica” de Marx resiste às "definições definitivas e fixas das classes". "Crítica da razão sociológica”, a abordagem marxiana das classes é de outra ordem, “estratégica”, na qual a luta política joga um papel central.

Previamente determinada no "laboratório secreto da produção”, analisado por Marx no livro I d'O Capital - no qual é revelada a “origem” do valor na exploração do trabalho -, a conceituação das classes sociais, na obra do filósofo alemão, passa também pelos níveis da circulação e da reprodução global, cujas análises foram apenas esboçadas nos incompletos livros II e III, respectivamente, d'O Capital. Cada nível sobrepõe uma nova determinação, no âmbito de uma relação que não se concretiza efetivamente senão no antagonismo dinâmico das classes em conflito latente.

Ora, se a relação entre as classes remete, no limite, ao aleatório da luta política, e se, como diria Gramsci, "só se pode prever a luta, não o seu desfecho”, não existe, em Marx, de acordo com Bensaïd, uma filosofia especulativa da história buscando determinar de antemão o destino do mundo. "Pensador da luta e não da lei, Marx não é um filósofo da história. É um pensador estratégi- co da ação política”, diz Bensaïd. Marx é um crítico radical da "razão histórica", uma vez que sua concepção de uma "história aberta" repele toda ideia de uma "normalidade" histórica - para a qual o presente é o resultado "necessário" do passado, no desenrolar de um tempo "vazio e homogêneo", bem acomodado ao "progresso" dos vencedores.

Momento de seleção dos possíveis, a política, no Marx “intempestivo” de Daniel Bensaïd, não se reduz à "mera ilustração da lógica histórica”. O "despertar" da ação revolucionária constitui, como disse Walter Benjamin nas Passagens, o instante em que "a política passa à frente da história”, isto é, o momento em que as classes oprimidas logram quebrar o círculo vicioso da reprodução infernal do "sonho da história", que avaliza a continuidade da dominação capitalista. Daí a percepção inevitável de que "as revoluções nunca chegam na hora certa”, de que elas jamais se enquadram na "normalidade" abstrata do tempo dos relógios. Uma revolução, como acontecimento fundador, está sempre em contratempo, já que se configura como bifurcação da história.

Instado por seu objeto (o capital), Marx esboça, na ótica de Bensaïd, uma "nova escuta do tempo", que se revela na tentativa de compreender as temporalidades discordantes que se desdobram do circuito de reprodução global do capitalismo. Para Daniel Bensaïd, tal como um detetive que investiga o crime quase perfeito do capital, Marx descobre na mercadoria - por meio da análise do processo de produção - a síntese desse "assassinato anônimo", materializado na extorsão permanente de mais-valor subtraído do trabalho. Com o "tempo cíclico" dos movimentos de circulação e reprodução global do capital - estudado por Marx nos livro II e III d'O Capital -, o crime se realiza em toda sua complexidade, valendo-se das garantias materiais e instituições para a continuidade de sua execução.

É nessa tentativa de compreender "o estranho comportamento do seu inimigo" que, segundo o filósofo francês, Marx - como "criminólogo que investiga o assassino, o capital" - se vê diante da necessidade de outra racionalidade, de um "sa- 
ber negativo”, crítico e radicalmente antipositivista, capaz de apreender uma totalidade em movimento. Procedendo por totalizações provisórias e dinâmicas, na contramão de toda lógica formal, Marx acompanha criticamente o movimento do capital, desvendando suas "aparências enganosas".

Pois bem: ainda que o tom de sua leitura atualizadora seja sempre generosa-e, por vezes, pareça representar mais o que ele gostaria que fosse, no presente, do que Marx efetivamente foi, no passado -, Bensaïd não ofusca, por outro lado, as contradições que atravessam o pensamento do filósofo alemão, contradições que, muitas vezes, o impeliram à defesa pouco crítica do "progresso" e do "desenvolvimento das forças produtivas". Na ótica de Bensaïd, Marx, envolvido nas condições de possibilidade do seu tempo, não foi - e nem poderia ser - um “anjo verde", um ecologista avant la lettre. Tampouco, porém, ele pode ser considerado um "demônio produtivista”, uma vez que denunciou, de modo pioneiro, em sua crítica radical do capitalismo, os "mitos do progresso" e o seu potencial destrutivo com relação à natureza. Não por acaso, essa crítica pode ser o ponto de partida (não de chegada), hoje, para o desenvolvimento de uma perspectiva "ecossocialista”, desde que se consiga superar as tentações "produtivistas" e "progressistas" habitualmente vinculadas ao pensamento de Marx e ao marxismo.

Ao acentuar o "atual ainda ativo" de Marx, Bensaïd compreende sua obra não como um edifício monumental monolítico e fechado, e sim como uma teoria crítica da luta social e da mudança do mundo, uma teoria crítica não apenas no que diz respeito à análise do objeto, o capitalismo, senão também crítica em relação a si mesma. É a partir desse "marxismo aberto", de verniz benjaminiano, que o espectro de Marx pode voltar a ressurgir, não como assombração dogmática, mas como espírito portador de uma esperança que, para continuar a existir, exige ser permanentemente atualizada, sob o risco (inevitável) da heresia. Pois, como disse Benjamin nas "teses sobre o conceito de história”, em palavras que resumem bem a perspectiva assumida por Daniel Bensaïd: "o dom de atear ao passado a centelha da esperança pertence somente àquele historiador que está perpassado pela convicção de que também os mortos não estarão seguros diante do inimigo, se ele for vitorioso. $\mathrm{E}$ esse inimigo não tem cessado de vencer".

Recebido para publicação em 02 de dezembro de 2014 Aceito em 12 de abril de 2014

Fabio Mascaro Querido - Doutorando em Sociologia no IFCH-UNICAMP, com bolsa FAPESP, com parte do doutoramento em realização na École de Hauts Études en Sciences Sociales (EHESS) - bolsa BEPE-FAPESP. Tem experiência na área de Sociologia, com ênfase em Sociologia da Cultura, Sociologia dos Intelectuais e Teoria Sociológica, atuando principalmente nos seguintes temas: pensamento social, Michael Löwy, Walter Benjamin, Daniel Bensaïd, marxismo contemporâneo e crítica da modernidade. fabiomascaro@yahoo.com.br 
